\title{
The analysis of supply and demand shocks adjustment dynamics of the EU-15 countries
}

\author{
Petra ČERNÍKOVÁ, Masaryk University ${ }^{\mathrm{i}}$
}

\begin{abstract}
In this paper, we use structural vector autoregression model with two variables to decompose economic disturbances to supply and demand shocks. This allows us to compare supply and demand shocks adjustment dynamics of output and price level among the EU-15 countries. The symmetry of output and price responses to these two kinds of shocks is assessed on the basis of correlation analysis. For our purposes we work with data for the EU-15 countries for the period 1995-2009. Our results suggest higher symmetry in the adjustment process to supply shocks and differences regarding price responses to both kinds of shocks.
\end{abstract}

\section{Keywords}

Adjustment dynamics, demand shock, European union-15, supply shock, VAR model.

JEL Classification: C30, E00, E30

\footnotetext{
${ }^{i}$ Faculty of Economics and Administration, Masaryk University, Lipová 41, 60200 Brno-Pisárky, Czech Republic. petra.cernikova@mail.muni.cz
}

\section{Introduction}

Joining a currency union is a very important step for each economy which decides to do so. According to theory (see Mundell, 1961), the most important disadvantage concerns losing the monetary policy autonomy. This means that the country has no longer a possibility to adapt freely to potential asymmetric economic shocks via this policy and its instruments. Exchange rate (if there was a floating regime before entering a monetary union) can no more serve as a buffer for external imbalances. This can be very costly when the country is affected by an asymmetric shock. ${ }^{1}$ Asymmetric shocks cut down potential advantages of the currency union membership. Common currency is less suitable for countries also in a case when they are hit by a same kind of shock, but the response to the shock is different (Frenkel and Nickel, 2002). So the response is asymmetric. Hence our

\footnotetext{
${ }^{1}$ For more information on exchange rate regimes and shocks asymmetry see Babetski et al. (2003).
}

analysis focuses right on output and price responses to supply and demand shocks.

The aim of the paper is comparing the shock adjustment dynamics of selected countries. We try to compare how symmetric is the adjustment process to supply and demand shocks. Moreover we want to find out if the group of analysed countries reacts more similarly to supply or demand shocks. As we mentioned before, we do this to see if members of the monetary union within the EU perform different price and output response to these kinds of shocks. According to Frenkel and Nickel (2002) if two countries are hit by the same shock but output, wage, and price responses are different then different economic performance can induce disequilibria between member countries of a currency union. Thanks to impulse response functions based on our structural VAR, we are able to compare respond of each economy to shocks. We can compare the speed of adjustment to shocks as well. Then we will be able to say if the shock responses are synchronic or not. 
We perform our analysis on the group of the EU15 countries. We pay our attention both to countries that are members of the Eurozone ${ }^{2}$ and to those that are not. ${ }^{3}$ We decided to do so as we want to compare if the shock responses of countries outside the Eurozone are different. The shock responses of individual countries will be primarily compared with the results for the whole EU-15 as we want to see how much these countries differ from it. The United States of America were chosen as a benchmark allowing us to compare our results with the rest of the world.

The paper is organized as follows. We start our analysis with decomposing of disturbances to supply and demand. The description of the decomposition method with the related literature is presented in the next session. Then we focus on an analysis of the impulse responses of both output and prices to these shocks. Finally we calculate correlation coefficients to compare the symmetry of output and price responses among analysed countries.

\section{The methodology}

Methodology which is commonly used for decomposition of economic shocks to supply and demand disturbances originates in the work of Blanchard and Quah (1989). Blanchard and Quah proposed bivariate VAR model for separating supply and demand disturbances via their impact on output and employment. Their work was further extended by Bayoumi and Eichengreen (1992). They apply Blanchard and Quah approach to shocks decomposition, but they modified the technique a little. They analysed effects of supply and demand shocks on output and on prices instead of unemployment. We will describe the model very briefly in this paper. For further information see the papers of the above mentioned authors as they described the technique in detail. This technique was also used by Fidrmuc and Korhonen (2003) to assess the similarity of supply and demand shocks.

This model is based on AS-AD framework. We work with two variables and hence we have two equations, one for output changes and another for price changes. We suppose that the model can be written as an infinite moving average representation of our variables and the same number of shocks:

$$
\begin{aligned}
{\left[\Delta y_{t}, \Delta p_{t}\right]^{\prime} } & =A_{0} \varepsilon_{t}+A_{1} \varepsilon_{t-1}+A_{2} \varepsilon_{t-2}+\ldots= \\
& =\sum_{i=1}^{\infty} L^{i} A_{i}\left[\varepsilon_{d t}, \varepsilon_{s t}\right]^{\prime} .
\end{aligned}
$$

\footnotetext{
2 Austria, Belgium, Finland, France, Germany, Greece, Ireland, Italy, Luxembourg, Netherlands, Portugal, Spain.

${ }^{3}$ Denmark, Sweden, United Kingdom.
}

Where $\left[\Delta y_{t}, \Delta p_{t}\right]^{\prime}$ represent the logarithm of output and prices $\left(X_{t}\right) ;\left[\varepsilon_{d t}, \varepsilon_{s t}\right]^{\prime}$ is a vector of demand and supply shocks $\left(\varepsilon_{t}\right)$; matrix $A_{i}$ represent the impulse response function of the shocks to the variables; $L^{i}$ is the lag operator.

For solving the model we must impose some restrictions, which follow from ordering of our variables. We assume that demand shocks have just temporary effects on output, whereas supply shocks causes long run changes in the output. Long run effect of demand shocks to output is restricted to zero by the model. Hence we get the following restriction: ${ }^{4}$

$$
\sum_{i=0}^{\infty} a_{11}^{i}=0 .
$$

The restriction implies that the long run matrix is lower triangular and hence can be solved via Cholesky decomposition of the long-run covariance matrix. Thus defined model can be estimated using a vector autoregression.

Estimated VAR model can be then used for calculating underlying supply and demand shocks. To recover underlying supply and demand shocks we must transform the residuals $\left(\varepsilon_{t}\right)$ from the VAR model to those shocks. The vector of residuals $e_{\mathrm{t}}$ we got from the two estimated equations and the estimating equation becomes:

$$
X_{t}=e_{t}+C_{1} e_{t-1}+C_{2} e_{t-2}+\ldots=\sum_{i=1}^{\infty} L^{i} C_{i} e_{t} .
$$

Where $C_{i}$ represents estimated coefficients.

From equation (1) and (3) it follows $e_{t}=A_{0} \varepsilon_{t}$, and when $A_{i}=C_{i} A_{0}$ and $\sum_{i=1}^{\infty} A_{i}=\sum_{i=1}^{\infty} C_{i} A_{0}$ we are able to identify matrix $A_{0}$ and underlying supply and demand shocks. 5

Restrictions in our model tell us, how supply and demand shocks affect output, but they do not say anything about their impact on prices. As Bayoumi and Eichengreen says (1992): The aggregate-demandaggregate-supply model implies that demand shocks should raise prices in both the short and long run, while supply shocks should lower prices. Since these responses are not imposed, they can be thought of as

\footnotetext{
4 All restrictions are necessary for solving the model, but this one is fundamental. See Lütkepohl (2004).

${ }^{5}$ As matrix $A_{0}$ has four elements, we need four restriction to identify it uniquely. Two are just normalizations defining the variance of the shocks $\varepsilon_{d t}$ and $\varepsilon_{s t}$. Assumption that supply and demand shocks are orthogonal is the third one. The equation (2) is the last one restriction.
} 
over-identifying restriction useful for testing our interpretation of the results.

To estimate our model we needed to set the optimal lag length. Optimal lag length for each country was chosen primarily on the basis of the Akaike information criterion (AIC). In some cases we consider as well other information criteria (Hannah-Quinn and Schwartz criterion) as we had to change the optimal lag length in order to preserve stability of given VAR model. Akaike information criterion suggested different optimal lags for the analysed countries; hence lags for different countries differ from one to four. For our calculations we used program called JMulTi, which serves for analysing of multiple time series. ${ }^{6}$

\section{The data}

We work with real GDP and deflator GDP in our analysis. The GDP deflator was calculated as a nominal (GDP/real GDP)'100. Our data were collected from the OECD Quarterly National Accounts database. We use quarterly data since 1995 Q1 to 2009 Q4, with some exceptions - Ireland and Greece since 2000 Q1. Earlier data were not available for these countries.

For purposes of our analysis we transformed all our data to the first differences of the logarithm of the real GDP and the implicit GDP deflator. We work only with transformed data as the original data were not stationary. Bayoumi and Eichengreen (1992) states: The GDP deflator was used to measure prices since it reflects the price of output rather than the price of consumption.

\footnotetext{
${ }^{6}$ For details see Lütkepohl and Krätzig (2007).
}

\section{Tests for stability}

When estimating the VAR models for all countries, we perform tests for stability as well. The stability of estimated parameters was examined by the CUSUM test. For almost all countries there is no evidence against structural instability of estimated model at the significance level $5 \%$. For Spain we could observe little violation of stability for the price equation in our model, probably thanks to a structural break in 2007.

The stationarity of transformed time series was tested via the augmented Dickey-Fuller test (ADF). All time series of GDP proved to be stationary as we were able to reject the unit root null hypothesis (see the Table 1). When analysing time series for gdp deflator we found some of then non stationary, what is probably caused by some little structural breaks (as we mentioned before in a case of Spain). Our time series fulfil the ADF test without these breaks.

\section{Supply and demand shock decomposition}

Following Figure 1 and the Figure 2 illustrate supply and demand shocks for the whole EU-15 and the USA. The Figure 1 shows impulse response functions of output and the Figure 2 response of prices. As we are interested in the effects of structural shocks on output and price level, we work with accumulated impulse responses of one standard deviation size. Our results confirm the assumption that supply shocks gradually raise output to a new higher level. On the other hand, demand shocks have just temporary effect on output. As we can see on the Figure 1 below, demand shocks raise output initially but then it returns to its original level. There is no permanent change in output caused by demand shocks.

Effects of supply and demand shocks on prices are generally viewed as so called over-identifying restricttions. The Figure 2 confirms that both supply and

Table 1 ADF test for analysed time series

\begin{tabular}{|c|c|c|c|c|c|c|c|c|c|}
\hline & \multicolumn{4}{|c|}{ variable } & & \multicolumn{4}{|c|}{ variable } \\
\hline & \multicolumn{2}{|c|}{ GDP } & \multicolumn{2}{|c|}{ price } & & \multicolumn{2}{|c|}{ GDP } & \multicolumn{2}{|c|}{ price } \\
\hline & tstat & tcrit & tstat & tcrit & & tstat & tcrit & tstat & tcrit \\
\hline $\mathrm{AT}$ & -1.65 & -1.62 & -1.17 & -1.62 & LX & -1.95 & -1.62 & -1.94 & -1.62 \\
\hline BEL & -2.77 & -1.62 & -1.7 & -1.62 & $\mathrm{NL}$ & -1.78 & -1.62 & -1.68 & -1.62 \\
\hline FIN & -2.87 & -1.62 & -3.67 & -1.62 & $\mathrm{PT}$ & -2.22 & -1.62 & -1.65 & -1.62 \\
\hline FRA & -2.13 & -1.62 & -1.7 & -1.62 & ES & -1.71 & -1.62 & -1.23 & -1.62 \\
\hline GER & -3.52 & -1.62 & -1.67 & -1.62 & USA & -2.23 & -1.62 & -1.66 & -1.62 \\
\hline GRE & -1.57 & -1.62 & -1.12 & -1.62 & UK & -2.17 & -1.62 & -2.31 & -1.62 \\
\hline IRL & -2.83 & -1.62 & -2.86 & -1.62 & $\mathrm{DEN}$ & -1.96 & -1.62 & -1.34 & -1.62 \\
\hline ITL & -2.1 & -1.62 & -2.3 & -1.62 & SWE & -3.1 & -1.62 & -4.56 & -1.62 \\
\hline
\end{tabular}

Tstat $=\mathrm{t}-$ statistics, tcrit $=$ critical value $($ significance level $10 \%)$,

Source: OECD. Stat Extracts. National Accounts. 


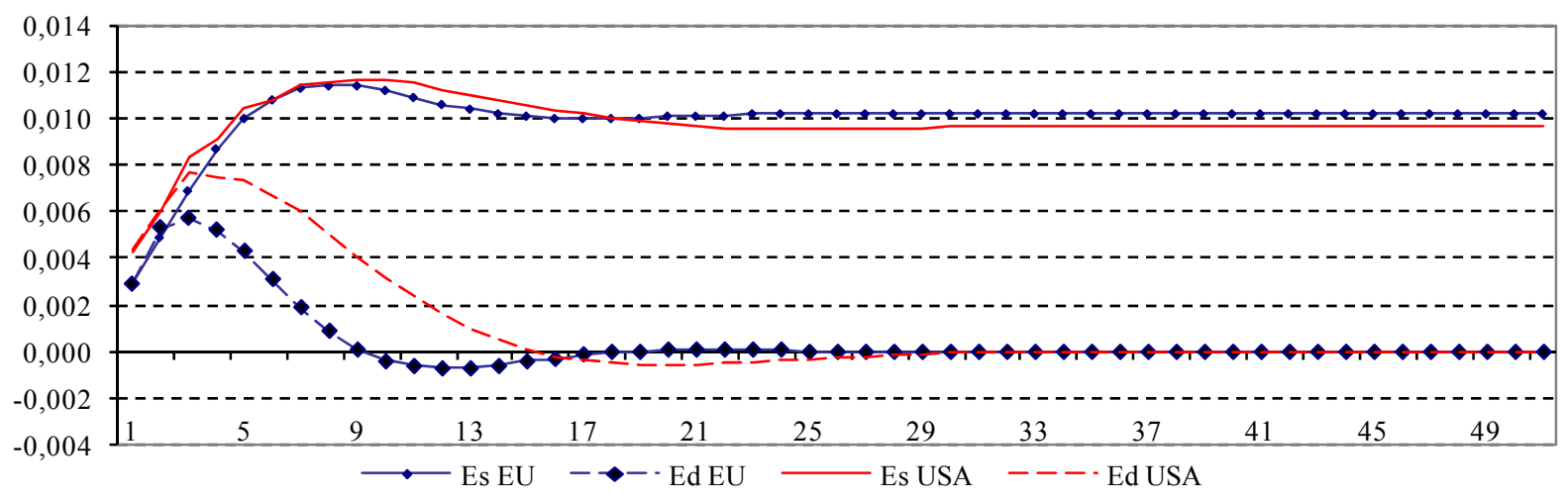

Figure 1 Impulse Response Function - Response of Output Note: Es - supply shock, Ed - demand shock. Source: OECD. Stat Extracts. Quarterly National Accounts.

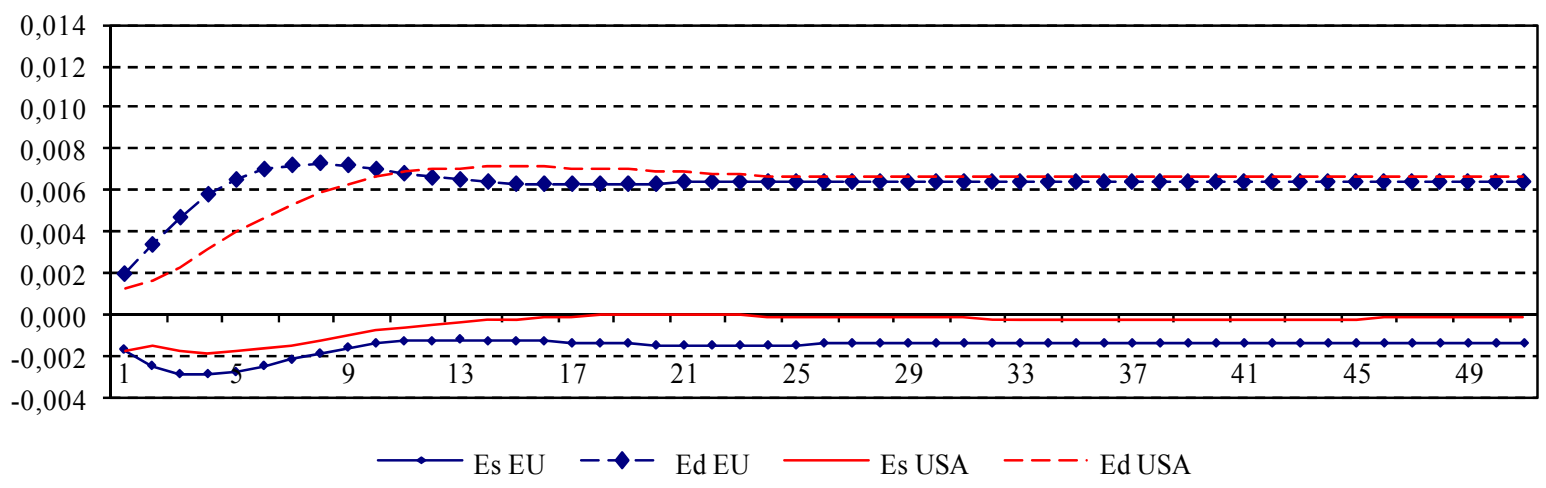

Figure 2 Impulse Response Function - Response of Prices Note: Es - supply shock, Ed - demand shock.

Data source: OECD. Stat Extracts. Quarterly National Accounts.

demand shocks have permanent effect on price level, in spite of very little effect of supply shocks on price level in the USA. While positive supply shocks lead to a decline in a price level, positive demand shocks result in an increase of price level.

Impulse response functions allow us to analyse shock adjustment dynamics. Moreover we use the correlation analysis to compare adjustment dynamics of analysed countries. Further we will be interested in a speed of adjustment to shocks.

\section{Shock adjustment dynamics of the analysed countries}

This section deals with adjustment dynamics of analysed countries to supply and demand shocks. We will deal with responses of output first and then with responses of prices. When we compare the shock adjustment dynamics to supply and demand shocks, we realize that the synchronization of adjustment is clearly higher for supply shocks.

As we mentioned in the introduction, our model does not impose any restriction to shocks effect on prices. We treat these responses as over-identifying restrictions. Unfortunately these restrictions were not fulfilled for some countries. These countries are Ireland, Greece, Portugal and Sweden. Hence we should take this information to our consideration.

\subsection{Supply shocks - response of output ${ }^{7}$}

Concerning supply shocks, the correlation of adjustment dynamics is high for almost all EU-15 countries (see the Table 2 and the Table 3). Almost all countries exhibit high correlation to the EU-15 and moreover they exhibit high cross correlations. There are just two countries with lower values of correlation coefficients of output response to supply shocks, when compared with the whole EU-15 and the rest of the EU-15.

Spanish supply shock response with the EU-15 is slightly over the boundary of high correlation. Spanish supply shocks adjustment dynamics correlations are

\footnotetext{
7 In this chapter we will deal with supply shocks and response of output but to make it easier will call them just supply shocks.
} 
high with some EU-15 countries and with some of them are on the boundary of high correlation (i.e. Belgium, France, Sweden).

As we can see on the Table 2, the Irish output response to supply shocks is not highly correlated, the correlation is low. This rules also with the individual EU-15 countries. Just with Sweden we can observe high correlation of output response to supply shocks.

Within the whole EU-15 there is no country with a strong negative correlation to any single country or the whole EU-15. Hence we found out that output responses to supply shocks are in the EU-15, with exceptions mentioned before, quite similar.

Generally all the EU-15 countries demonstrate at least slowly higher correlation to the EU-15 than to the USA. Almost all EU-15 countries exhibit strong shock adjustment dynamics correlation with the USA.
There are just two exceptions - Ireland and Spain. Output response to the supply shocks of these countries is lowly correlated with the American one. Relatively lower value of correlation exhibit as well Denmark (see Table 3).

\subsection{Demand shocks - response of output ${ }^{8}$}

Responses of output to demand shocks are noticeably less correlated than output responses to supply shocks (compare the Table 4 and the Table 2). Results measured for output response of demand shocks were influence by different kind of shocks that were identi-

\footnotetext{
${ }^{8}$ In this chapter we will deal with demand shocks and response of output, but to make it easier will call them just demand shocks.
}

Table 2 Correlation Coefficients of Output Response to Supply Shocks for the Euroarea-12 Countries

\begin{tabular}{|c|c|c|c|c|c|c|c|c|c|c|c|c|c|c|}
\hline & AT & BEL & FIN & FRA & GER & GRE & IRL & ITL & LX & NL & PT & ES & EU15 \\
\hline \multicolumn{3}{|c|}{} & \multicolumn{7}{|c|}{ Supply Shocks- Impulse Response of Output } & \\
\hline AT & & & & & & & & & & & & \\
\hline BEL & 0.91 & & & & & & & & & & & & \\
\hline FIN & 0.96 & 0.99 & & & & & & & & & & & \\
\hline FRA & 0.88 & 1.00 & 0.97 & & & & & & & & & & \\
\hline GER & 0.98 & 0.95 & 0.98 & 0.92 & & & & & & & & & \\
\hline GRE & 0.98 & 0.96 & 0.99 & 0.94 & 1.00 & & & & & & & & \\
\hline IRL & 0.41 & 0.48 & 0.47 & 0.51 & 0.41 & 0.40 & & & & & & & \\
\hline ITL & 0.98 & 0.95 & 0.99 & 0.92 & 1.00 & 1.00 & 0.40 & & & & & & \\
\hline LX & 0.83 & 0.77 & 0.81 & 0.73 & 0.85 & 0.86 & -0.12 & 0.86 & & & & & \\
\hline NL & 0.96 & 0.99 & 1.00 & 0.97 & 0.98 & 0.99 & 0.48 & 0.98 & 0.80 & & & & \\
\hline PT & 0.97 & 0.89 & 0.94 & 0.85 & 0.98 & 0.98 & 0.28 & 0.98 & 0.90 & 0.94 & & & \\
\hline ES & 0.73 & 0.60 & 0.69 & 0.54 & 0.78 & 0.75 & 0.17 & 0.78 & 0.70 & 0.68 & 0.84 & & \\
\hline EU15 & $\mathbf{0 . 9 4}$ & $\mathbf{0 . 9 2}$ & $\mathbf{0 . 9 4}$ & $\mathbf{0 . 9 1}$ & $\mathbf{0 . 9 4}$ & $\mathbf{0 . 9 5}$ & $\mathbf{0 . 3 1}$ & $\mathbf{0 . 9 4}$ & $\mathbf{0 . 8 7}$ & $\mathbf{0 . 9 4}$ & $\mathbf{0 . 9 2}$ & $\mathbf{0 . 5 9}$ & \\
\hline USA & 0.84 & 0.83 & 0.82 & 0.83 & 0.79 & 0.82 & 0.29 & 0.80 & 0.73 & 0.83 & 0.75 & 0.29 & 0.92 \\
\hline
\end{tabular}

Note: Correlation coefficients are computed on the impulse response functions of output to supply shocks.

Data source: OECD. Stat Extracts. Quarterly National Accounts.

Table 3 Correlation Coefficients of Output Response to Supply Shocks for the Non Euroarea-12 Member Countries from the EU-15

\begin{tabular}{|c|c|c|c|c|c|c|c|c|c|c|c|c|c|}
\hline & UK & SWE & DEN & & UK & SWE & DEN & & UK & SWE & DEN \\
\hline \multicolumn{10}{|c|}{ Supply Shocks- Impulse Response of Output } \\
\hline AT & 0.97 & 0.91 & 0.84 & IRL & 0.31 & 0.60 & 0.06 & EU15 & $\mathbf{0 . 8 9}$ & $\mathbf{0 . 8 8}$ & $\mathbf{0 . 7 5}$ \\
\hline BEL & 0.88 & 0.99 & 0.70 & ITL & 0.98 & 0.94 & 0.87 & USA & 0.72 & 0.80 & 0.52 \\
\hline FIN & 0.94 & 0.98 & 0.78 & LX & 0.88 & 0.68 & 0.88 & UK & x & 0.86 & 0.94 \\
\hline FRA & 0.84 & 0.99 & 0.64 & NL & 0.94 & 0.98 & 0.78 & SWE & 0.86 & x & 0.66 \\
\hline GER & 0.98 & 0.94 & 0.87 & PT & 1.00 & 0.86 & 0.94 & DEN & 0.94 & 0.66 & x \\
\hline GRE & 0.97 & 0.95 & 0.85 & ES & 0.86 & 0.59 & 0.93 & & & & \\
\hline
\end{tabular}

Note: Correlation coefficients are computed on the impulse response functions of output to supply shocks.

Data source: OECD. Stat Extracts. Quarterly National Accounts. 
fied. For most countries we identified positive demand shocks, but for Greece, Italy, Netherlands and Portugal we identified negative demand shocks. We should take these findings into account as it influences correlation coefficients that were measured.

Almost all countries that were affected by positive demand shock exhibit strong correlation to the EU-15. We can observe slightly lower correlation between Luxembourg and the EU-15 and its individual countries as well, but these values can be still interpreted as a strong correlation. For Ireland and Sweden we can practically observe no correlation of output response to demand shocks. Anyway, the test for statistical significance of correlation coefficient showed no significance of many values measured for Ireland and for some correlation coefficients measured for Sweden (including the ones with the EU-15). Hence we are unable to make any conclusions for these two countries.

There are four countries for which we identified as a structural shock the negative demand shock. These countries are Greece, Italy, Netherlands and Portugal. Their shock adjustment dynamics to demand shocks are strongly negatively correlated with the EU-15. Hence we could expect strong correlations with the EU-15, if these countries were affected by positive demand shocks.

Results for the individual countries correspond with above mentioned findings. Countries with strong correlations with the EU-15 exhibit mainly strong correlations with each other (i.e. Belgium - France).
The same rules for the countries, for which we identified negative demand shocks.

All of the EU-15 countries manifest slightly higher correlations of demands shocks adjustment dynamics with the EU-15 than with the USA. As we can see on the Table 4, the American shock adjustment dynamics is highly correlated with the EU-15 one. Hence our results of the individual EU countries with the EU-15 are quite identical with those of the individual EU countries with the USA.

Output reaction to demand shocks is among the EU-15 countries less correlated than the output reaction to supply shocks. This is obvious especially when we look at the correlations among the individual EU countries (the Table 4 and the Table 5). For some countries we identified negative demand shocks as structural shocks. This gives us information that during the analysed period there were demand shocks which were for some countries positive and for some of them negative. Hence this might imply existence of idiosyncratic demand shocks within the EU.

\subsection{Supply shocks - response of prices ${ }^{9}$}

Response of prices to supply shocks serves us as an important over-identifying restriction. This one is probably the most important. We use it to test the

\footnotetext{
9 In this chapter we will deal with demand shocks and response of output but to make it easier will call them just demand shocks.
}

Table 4 Correlation Coefficients of Output Response to Demand Shocks for the Euroarea-12 Countries

\begin{tabular}{|c|c|c|c|c|c|c|c|c|c|c|c|c|c|}
\hline & AT & BEL & FIN & FRA & GER & GRE & IRL & ITL & LX & NL & PT & ES & EU15 \\
\hline & \multicolumn{9}{|c|}{ Demand Shocks- Impulse Response of Output } & \\
\hline AT & & & & & & & & & & & & & \\
\hline BEL & 0.58 & & & & & & & & & & & & \\
\hline FIN & 0.55 & 0.97 & & & & & & & & & & & \\
\hline FRA & 0.67 & 0.99 & 0.96 & & & & & & & & & & \\
\hline GER & 0.44 & 0.88 & 0.96 & 0.86 & & & & & & & & & \\
\hline GRE & -0.44 & -0.85 & -0.94 & -0.85 & -0.98 & & & & & & & & \\
\hline IRL & 0.08 & 0.45 & 0.64 & 0.46 & 0.79 & -0.85 & & & & & & & \\
\hline ITL & -0.80 & -0.92 & -0.86 & -0.94 & -0.75 & 0.72 & -0.27 & & & & & & \\
\hline LX & 0.41 & 0.52 & 0.37 & 0.50 & 0.17 & -0.20 & -0.18 & -0.47 & & & & & \\
\hline NL & -0.43 & -0.91 & -0.95 & -0.90 & -0.94 & 0.96 & -0.75 & 0.75 & -0.42 & & & & \\
\hline PT & -0.47 & -0.87 & -0.96 & -0.86 & -0.99 & 0.96 & -0.77 & 0.76 & -0.12 & 0.91 & & & \\
\hline ES & 0.75 & 0.84 & 0.81 & 0.82 & 0.74 & -0.66 & 0.24 & -0.90 & 0.40 & -0.67 & -0.77 & & \\
\hline EU15 & $\mathbf{0 . 9 3}$ & $\mathbf{0 . 7 4}$ & $\mathbf{0 . 7 0}$ & $\mathbf{0 . 8 2}$ & $\mathbf{0 . 5 6}$ & $\mathbf{- 0 . 5 7}$ & $\mathbf{0 . 1 6}$ & $\mathbf{- 0 . 8 9}$ & $\mathbf{0 . 4 7}$ & $\mathbf{- 0 . 5 7}$ & $\mathbf{- 0 . 5 9}$ & $\mathbf{0 . 7 6}$ & \\
\hline USA & 0.98 & 0.54 & 0.54 & 0.62 & 0.46 & -0.46 & 0.14 & -0.75 & 0.35 & -0.43 & -0.49 & 0.76 & 0.86 \\
\hline
\end{tabular}

Note: Correlation coefficients are computed on the impulse response functions of output to demand shocks.

Data source: OECD. Stat Extracts. Quarterly National Accounts. 
interpreting ability of our results. According to our assumptions, supply shocks should lead into a drop in a price level. Unfortunately results for some countries do not fulfil this presumption. Results for Greece, Ireland, Portugal and Spain did not fulfil given restriction. We can observe increase in a price level for them in spite of being affected by positive supply shocks.

Let' s starts with an assessment of individual country's correlations to the EU-15 (see the Table 6). We can classify the analysed countries into few groups. The first one covers countries with strong correlations of price response to supply shocks with the whole EU15. These countries are Austria, Belgium, France, Italy, Netherlands, Portugal, Spain and finally the United Kingdom. On the contrary just Germany demonstrates strong negative correlation of its price response. Ireland exhibits no price response correla- tion to the EU-15. Anyway this correlation coefficient is statistically not significant according to our analysis. From this point of view we could doubt about the results for Austria as many correlation coefficients of the country proved not to be significant. The rest of the EU-15 countries have their prices responses to demand shocks just slightly correlated.

When analysing supply shock adjustment dynamics of prices within the EU-15, we find similar results to those ones when we were analysing individual countries with the EU-15. The lowest values of correlations with other countries exhibit Germany, which price response is strongly negatively correlated with most of the EU-15 countries. The same rules for Sweden as well (see the Table 7). Mutually highest synchronization of price responses to supply shocks demonstrates Belgium, Finland, France, Greece, Italy, Portugal, Spain, the UK and Denmark.

Table 5 Correlation Coefficients of Output Response to Demand Shocks for the Non Euroarea-12 Member Countries from the EU-15

\begin{tabular}{|c|c|c|c|c|c|c|c|c|c|c|c|c|c|}
\hline & UK & SWE & DEN & & UK & SWE & DEN & & UK & SWE & DEN \\
\hline \multicolumn{10}{|c|}{ Demand Shocks- Impulse Response of Output } \\
\hline AT & 0.67 & 0.17 & 0.82 & IRL & 0.68 & 0.98 & 0.46 & EU15 & $\mathbf{0 . 7 8}$ & $\mathbf{0 . 2 8}$ & $\mathbf{0 . 8 6}$ \\
\hline BEL & 0.90 & 0.60 & 0.90 & ITL & -0.88 & -0.41 & -0.95 & USA & 0.66 & 0.23 & 0.80 \\
\hline FIN & 0.95 & 0.75 & 0.89 & LX & 0.27 & -0.03 & 0.42 & UK & X & 0.77 & 0.94 \\
\hline FRA & 0.93 & 0.60 & 0.94 & NL & -0.91 & -0.85 & -0.83 & SWE & 0.77 & $x$ & 0.59 \\
\hline GER & 0.94 & 0.87 & 0.82 & PT & -0.94 & -0.85 & -0.82 & DEN & 0.94 & 0.59 & x \\
\hline GRE & -0.94 & -0.93 & -0.82 & ES & 0.79 & 0.37 & 0.86 & & & & \\
\hline
\end{tabular}

Note: Correlation coefficients are computed on the impulse response functions of output to demand shocks.

Data source: OECD. Stat Extracts. Quarterly National Accounts.

Table 6 Correlation Coefficients of Price Response to Supply Shocks for the Euroarea-12 Countries

\begin{tabular}{|c|c|c|c|c|c|c|c|c|c|c|c|c|c|}
\hline & $\mathrm{AT}$ & BEL & FIN & FRA & GER & GRE & IRL & ITL & LX & NL & PT & ES & EU15 \\
\hline & \multicolumn{13}{|c|}{ Supply Shocks- Impulse Response of Prices } \\
\hline AT & & & & & & & & & & & & & \\
\hline BEL & -0.16 & & & & & & & & & & & & \\
\hline FIN & -0.36 & 0.93 & & & & & & & & & & & \\
\hline FRA & 0.13 & 0.93 & 0.80 & & & & & & & & & & \\
\hline GER & 0.15 & -0.99 & -0.96 & -0.91 & & & & & & & & & \\
\hline GRE & -0.33 & 0.91 & 0.99 & 0.79 & -0.95 & & & & & & & & \\
\hline IRL & -0.63 & 0.37 & 0.68 & 0.19 & -0.46 & 0.72 & & & & & & & \\
\hline ITL & -0.08 & 0.97 & 0.94 & 0.95 & -0.99 & 0.94 & 0.45 & & & & & & \\
\hline LX & -0.01 & 0.57 & 0.47 & 0.55 & -0.54 & 0.43 & 0.07 & 0.51 & & & & & \\
\hline NL & 0.02 & 0.72 & 0.49 & 0.62 & -0.65 & 0.43 & -0.22 & 0.59 & 0.40 & & & & \\
\hline $\mathrm{PT}$ & -0.26 & 0.94 & 0.99 & 0.84 & -0.97 & 0.99 & 0.62 & 0.97 & 0.42 & 0.53 & & & \\
\hline ES & 0.33 & 0.74 & 0.71 & 0.79 & -0.79 & 0.73 & 0.30 & 0.82 & 0.36 & 0.42 & 0.77 & & \\
\hline EU15 & 0.58 & 0.56 & 0.45 & 0.77 & -0.60 & 0.48 & -0.02 & 0.68 & 0.25 & 0.32 & 0.54 & 0.78 & \\
\hline USA & 0.46 & 0.62 & 0.60 & 0.73 & -0.69 & 0.65 & 0.26 & 0.75 & 0.23 & 0.28 & 0.68 & 0.92 & 0.87 \\
\hline
\end{tabular}

Note: Correlation coefficients are computed on the impulse response functions of prices to supply shocks.

Data source: OECD. Stat Extracts. Quarterly National Accounts. 
Let's have a look at the correlations with the rest of the world represented by the United States of America. As we can see on the Table 6, the American shock adjustment dynamics is highly correlated with the EU-15 one. Hence the results of the individual EU countries with the USA are quite identical with those of the individual EU countries with the EU-15.

\subsection{Demand shocks - response of prices ${ }^{10}$}

Price responses to demand shocks are across the EU15 less correlated than they were for supply shocks. There are obviously more countries with strong negative correlations within each other.

Concerning price response to demand shocks, we can find two groups of countries with some specifics. Austria, Finland, France, Greece, Netherlands demonstrate strong price response correlations to the EU-15. Price response to demand shock is within this group of countries highly correlated as well. Demand shocks lead to gradual increase in price levels in these countries. Germany could be as well part of this group, in spite slightly lower values of measured correlation coefficients. On the other hand, in other countries, demand shocks lead to initial higher increase in price levels and then it go back to its new equilibrium level. These countries - Ireland, Luxembourg, Spain, the UK, Sweden and Denmark have strong negative correlations with the EU-15 and with the above mentioned countries as well (see the Table 8 and the Table 9). Rest of the EU-15 belongs rather to the latter group.

Correlation of price responses to demand shocks between the USA and the EU-15 is again strong. This greatly influences results of individual EU-15 countries with the USA. Countries with the strong correlation with the EU-15 exhibit strong correlation with the USA and vice versa.

To conclude this part of analysis we deal with correlations of price responses to demand shocks among the individual EU-15 countries. We identified two groups of countries with different initial price reactions to the demand shocks. All three countries that refused to adopt the euro as their currency, demonstrate strong negative correlations with the EU-15.

\section{Speed of adjustment to shocks}

Impulse response analysis gives us a possibility to compare a speed of adjustment to shocks of individual countries. We use Bayoumi and Eichengreen's meth-

\footnotetext{
10 In this chapter we will deal with demand shocks and response of prices, but to make it easier will call them just demand shocks.
}

odology (1992) and hence we calculate the speed of adjustment as a ratio of the value of the impulse response function in a third year to its long run level. ${ }^{11}$ To analyse speed of adjustment we focus just on the influence of supply and demand shocks on output. ${ }^{12}$

\subsection{Supply shocks}

Results for the output responses to supply shocks are shown the next Table 10. For simplification we computed absolute percentage deviation from long run value. As we can see, most of analysed countries adapt to shock very quickly, except Spain. Generally the speed of adjustment to supply shocks is quite high.

For some countries we observe initial overshooting of output long run level. This explains why the adjustment ratios of some countries are higher than $100 \%$ of the long run level of output (Austria, EU-15 and USA). As we can see on the Table 10, the EU-15 adapts to supply shocks faster than the USA does, in spite of almost identical magnitude of measured shock.

We can conclude that within the group of analysed countries, there exist no significant differences in the speed of adjustment to these shocks. Some countries (Austria, Spain and Denmark) adapt to shock relatively slowly than other countries.

\subsection{Demand shocks}

For analysing output response of demand shocks we can not use Bayoumi and Eichengreen's methodology (1992) as the long run value of output is zero. As we know that the long run value of the output is zero, we find out the speed of adjustment just by comparing the moment when the zero value is reached.

Countries with the fastest speed of adjustment are Ireland, Netherlands and Sweden. Again rules that most of the countries adapt to demand shocks very quickly. Slower reaction of output to demand shocks demonstrate Austria, EU-15, USA and Denmark. These are the same countries, which adapt to supply shocks relative slower, when comparing with other countries.

\subsection{Test of significance of correlation coefficients}

To support our results we performed the test of significance of correlation coefficients. The correlation coefficients of individual countries with the EU-15

\footnotetext{
11 The third year was chosen as it is approximately quarter of the period for which we analyse impulse response functions (12 quarters out of 50).

12 Over-identifying restrictions were not fulfilled for the price response to supply shocks and hence we focus just on the output response to supply and demand shocks.
} 
and with each other were examined using t-statistics. Here we just present results of these tests for the individual countries and the whole EU-15 (see the following Table 11).
As we can see, not all correlations for the whole analysed period are statistically significant at the $5 \%$ level of significance. Anyway there are just few not

Table 7 Correlation Coefficients of Price Response to Supply Shocks for the Non Euroarea-12 Member Countries from the EU-15

\begin{tabular}{|c|c|c|c|c|c|c|c|c|c|c|c|c|c|c|}
\hline & UK & SWE & DEN & & UK & SWE & DEN & & UK & SWE & DEN \\
\hline & \multicolumn{9}{|c|}{ Supply Shocks- Impulse Response of Prices } \\
\hline AT & -0.17 & 0.43 & -0.28 & IRL & 0.60 & -0.71 & 0.83 & EU15 & $\mathbf{0 . 6 2}$ & $-\mathbf{0 . 3 6}$ & $\mathbf{0 . 4 3}$ \\
\hline BEL & 0.94 & -0.90 & 0.71 & ITL & 0.98 & -0.90 & 0.79 & USA & 0.75 & -0.54 & 0.65 \\
\hline FIN & 0.97 & -0.99 & 0.88 & LX & 0.43 & -0.38 & 0.38 & UK & X & -0.95 & 0.87 \\
\hline FRA & 0.88 & -0.74 & 0.63 & NL & 0.48 & -0.49 & 0.09 & SWE & -0.95 & X & -0.86 \\
\hline GER & -0.97 & 0.93 & -0.77 & PT & 0.99 & -0.97 & 0.86 & DEN & 0.87 & -0.86 & X \\
\hline GRE & 0.98 & -0.98 & 0.91 & ES & 0.81 & -0.65 & 0.71 & & & & \\
\hline
\end{tabular}

Note: Correlation coefficients are computed on the impulse response functions of prices to supply shocks.

Data source: OECD. Stat Extracts. Quarterly National Accounts.

Table 8 Correlation Coefficients of Price Response to Demand Shocks for the Euroarea-12 Countries

\begin{tabular}{|c|c|c|c|c|c|c|c|c|c|c|c|c|c|}
\hline & AT & BEL & FIN & FRA & GER & GRE & IRL & ITL & LX & NL & PT & ES & EU15 \\
\hline & \multicolumn{13}{|c|}{ Demand Shocks- Impulse Response of Prices } \\
\hline AT & & & & & & & & & & & & & \\
\hline BEL & -0.43 & & & & & & & & & & & & \\
\hline FIN & 0.72 & 0.25 & & & & & & & & & & & \\
\hline FRA & 0.80 & 0.09 & 0.95 & & & & & & & & & & \\
\hline GER & 0.53 & -0.02 & 0.50 & 0.38 & & & & & & & & & \\
\hline GRE & 0.79 & -0.77 & 0.22 & 0.43 & 0.08 & & & & & & & & \\
\hline IRL & -0.60 & -0.39 & -0.97 & -0.87 & -0.57 & -0.03 & & & & & & & \\
\hline ITL & 0.16 & -0.65 & -0.20 & -0.03 & -0.56 & 0.57 & 0.36 & & & & & & \\
\hline LX & -0.71 & -0.24 & -0.93 & -0.96 & -0.27 & -0.35 & 0.86 & 0.11 & & & & & \\
\hline NL & 0.65 & 0.34 & 0.99 & 0.90 & 0.57 & 0.10 & -1.00 & -0.32 & -0.89 & & & & \\
\hline $\mathrm{PT}$ & -0.11 & -0.51 & -0.65 & -0.56 & 0.18 & 0.22 & 0.66 & 0.01 & 0.64 & -0.64 & & & \\
\hline ES & -0.79 & -0.12 & -0.91 & -0.91 & -0.64 & -0.36 & 0.87 & 0.30 & 0.88 & -0.90 & 0.36 & & \\
\hline EU15 & 0.88 & -0.20 & 0.81 & 0.91 & 0.42 & 0.60 & -0.69 & 0.09 & -0.83 & 0.74 & -0.31 & -0.83 & \\
\hline USA & 0.98 & -0.53 & 0.60 & 0.67 & 0.53 & 0.83 & -0.48 & 0.19 & -0.59 & 0.53 & 0.03 & -0.69 & 0.76 \\
\hline
\end{tabular}

Note: Correlation coefficients are computed on the impulse response functions of prices to demand shocks.

Data source: OECD. Stat Extracts. Quarterly National Accounts.

Table 9 Correlation Coefficients of Price Response to Demand Shocks for the Non Euroarea-12 Member Countries from the EU-15

\begin{tabular}{|c|c|c|c|c|c|c|c|c|c|c|c|c|c|c|c|}
\hline & UK & SWE & DEN & & & UK & SWE & DEN & & UK & SWE & DEN \\
\hline \multicolumn{10}{|c|}{ Demand Shocks- Impulse Response of Prices } \\
\hline AT & -0.54 & -0.41 & -0.82 & & IRL & 0.99 & 0.95 & 0.67 & EU15 & $\mathbf{- 0 . 6 3}$ & $\mathbf{- 0 . 5 2}$ & $\mathbf{- 0 . 8 4}$ \\
\hline BEL & -0.45 & -0.55 & 0.06 & & ITL & 0.46 & 0.63 & 0.26 & USA & -0.42 & -0.30 & -0.75 \\
\hline FIN & -0.94 & -0.86 & -0.76 & & LX & 0.80 & 0.70 & 0.82 & UK & X & 0.98 & 0.64 \\
\hline FRA & -0.81 & -0.70 & -0.84 & & NL & -0.98 & -0.92 & -0.72 & SWE & 0.98 & X & 0.59 \\
\hline GER & -0.64 & -0.69 & -0.55 & & PT & 0.61 & 0.53 & 0.16 & DEN & 0.64 & 0.59 & X \\
\hline GRE & 0.06 & 0.21 & -0.54 & & ES & 0.85 & 0.80 & 0.90 & & & & & \\
\hline
\end{tabular}

Note: Correlation coefficients are computed on the impulse response functions of prices to demand shocks.

Data source: OECD. Stat Extracts. Quarterly National Accounts. 
significant values (two for Ireland) and hence this should not influence our analysis greatly.

As we mentioned before, we tested all correlation coefficient among the individual EU-15 countries as well. Almost all correlation coefficients measured for output response to supply shocks are statistically significant. Only those among Ireland and Spain and Luxembourg proved not to be significant. Results for output response to demand shocks among Ireland, Luxembourg and some EU-15 countries showed not to be significant. Concerning the price response to supply shocks we again observe few insignificant correlations for Ireland, Luxembourg and Austria. Relatively worse results we got for price response to demand shocks. We can have doubts about some results for Belgium, Greece and Italy. Anyway the most important for our analysis are correlations of individual countries with the EU-15 and from this point of view; almost all results are statistically significant.

\section{Conclusion}

This paper focused on the analysis of supply and demand shocks adjustment dynamics. We decomposed shocks to supply and demand via VAR model. Then we analysed the impulse responses of both output and prices. Generally we observed clearly higher synchronization of supply shocks adjustment when compared with demand shocks.

Output responses to supply shocks are highly correlated among the EU-15 countries. Concerning the long run effect of supply shocks on output, we consider the high level of synchronization more important

Table 10 Output Speed of Adjustment to Supply Shocks

\begin{tabular}{|c|c|c|c|c|c|c|c|c|c|}
\hline & AT & BEL & FIN & FRA & GER & GRE & IRL & ITL & LX \\
\hline adjustment ratio & 105 & 99 & 100 & 100 & 99 & 100 & 100 & 100 & 100 \\
\hline deviation from long run value $-\%$ & 5 & 1 & 0 & 0 & 1 & 0 & 0 & 0 & 0 \\
\hline & $\mathrm{NL}$ & PT & ES & EU-15 & USA & UK & SWE & DEN & \\
\hline adjustment ratio & 100 & 99 & 70 & 104 & 115 & 98 & 100 & 91 & \\
\hline deviation from long run value $-\%$ & 0 & 1 & 30 & 4 & 15 & 2 & 0 & 9 & \\
\hline
\end{tabular}

Data source: OECD.Stat Extracts. Quarterly National Accounts.

Table 11 Significance of correlation coefficients of each country with the EU-15

\begin{tabular}{|c|c|c|c|c|c|c|c|c|c|c|c|c|}
\hline & \multicolumn{6}{|c|}{ Supply shocks } & \multicolumn{6}{|c|}{ Demand shocks } \\
\hline & \multicolumn{3}{|c|}{ Output response } & \multicolumn{3}{|c|}{ Price response } & \multicolumn{3}{|c|}{ Output response } & \multicolumn{3}{|c|}{ Price response } \\
\hline & tstat & tcrit & sign. & tstat & tcrit & sign. & tstat & tcrit & sign. & tstat & tcrit & sign. \\
\hline $\mathrm{AT}$ & 24.10 & 1.99 & $\mathrm{Y}$ & 4.9 & 2.01 & $\mathrm{Y}$ & 17.7 & 2.01 & $\mathrm{Y}$ & 12.7 & 2.01 & $\mathrm{Y}$ \\
\hline BEL & 21.30 & 1.99 & $\mathrm{Y}$ & 4.8 & 2.01 & $\mathrm{Y}$ & 7.6 & 2.01 & $\mathrm{Y}$ & 0 & 2.01 & $\mathrm{~N}$ \\
\hline FIN & 24.10 & 1.99 & $\mathrm{Y}$ & 3.5 & 2.01 & $\mathrm{Y}$ & 6.8 & 2.01 & $\mathrm{Y}$ & 9.7 & 2.01 & $\mathrm{Y}$ \\
\hline FRA & 18.70 & 1.99 & $\mathrm{Y}$ & 8.6 & 2.01 & $\mathrm{Y}$ & 10 & 2.01 & $\mathrm{Y}$ & 15.3 & 2.01 & $\mathrm{Y}$ \\
\hline GER & 23.80 & 1.99 & $\mathrm{Y}$ & -5.3 & 2.01 & $\mathrm{Y}$ & 4.8 & 2.01 & $\mathrm{Y}$ & 3.3 & 2.01 & $\mathrm{Y}$ \\
\hline GRE & 26.00 & 1.99 & $\mathrm{Y}$ & 3.8 & 2.01 & $\mathrm{Y}$ & -4.9 & 2.01 & $\mathrm{Y}$ & 5.2 & 2.01 & $\mathrm{Y}$ \\
\hline IRL & 2.90 & 1.99 & $\mathrm{Y}$ & -0.1 & 2.01 & $\mathrm{~N}$ & 1.11 & 2.01 & $\mathrm{~N}$ & -6.7 & 2.01 & $\mathrm{Y}$ \\
\hline ITL & 23.50 & 1.99 & $\mathrm{Y}$ & 6.6 & 2.01 & $\mathrm{Y}$ & -14 & 2.01 & $\mathrm{Y}$ & 0.6 & 2.01 & $\mathrm{~N}$ \\
\hline LX & 15.40 & 1.99 & $\mathrm{Y}$ & 1.8 & 2.01 & $\mathrm{~N}$ & 3.7 & 2.01 & $\mathrm{Y}$ & -10.5 & 2.01 & $\mathrm{Y}$ \\
\hline NL & 23.70 & 1.99 & $\mathrm{Y}$ & 2.4 & 2.01 & $\mathrm{Y}$ & -4.9 & 2.01 & $\mathrm{Y}$ & 7.7 & 2.01 & $\mathrm{Y}$ \\
\hline PT & 20.00 & 1.99 & $\mathrm{Y}$ & 4.5 & 2.01 & $\mathrm{Y}$ & -5.1 & 2.01 & $\mathrm{Y}$ & -2.3 & 2.01 & $\mathrm{Y}$ \\
\hline ES & 6.40 & 1.99 & $\mathrm{Y}$ & 8.8 & 2.01 & $\mathrm{Y}$ & 8.3 & 2.01 & $\mathrm{Y}$ & -10.4 & 2.01 & $\mathrm{Y}$ \\
\hline USA & 21.10 & 1.99 & $\mathrm{Y}$ & 12.5 & 2.01 & $\mathrm{Y}$ & 11.7 & 2.01 & $\mathrm{Y}$ & 8.1 & 2.01 & $\mathrm{Y}$ \\
\hline UK & 17.50 & 1.99 & $\mathrm{Y}$ & 5.6 & 2.01 & $\mathrm{Y}$ & 8.7 & 2.01 & $\mathrm{Y}$ & -5.6 & 2.01 & $\mathrm{Y}$ \\
\hline DEN & 16.70 & 1.99 & $\mathrm{Y}$ & -2.7 & 2.01 & $\mathrm{Y}$ & 2 & 2.01 & $\mathrm{~N}$ & -4.2 & 2.01 & $\mathrm{Y}$ \\
\hline SWE & 10.10 & 1.99 & $\mathrm{Y}$ & 3.3 & 2.01 & $\mathrm{Y}$ & 11.7 & 2.01 & $\mathrm{Y}$ & -11 & 2.01 & $\mathrm{Y}$ \\
\hline
\end{tabular}

Tstat $=\mathrm{t}-$ statistics, tcrit $=$ critical value (significance level $5 \%$ ), sign. $=$ significant - if yes, then the correlation coefficient is statistically significant.

Source: OECD. Stat Extracts. National Accounts. 
than the lower synchronization of output reaction to demand shocks.

Results for output response to demand shocks showed us, that for some analysed countries we identified as a structural shock positive demand shock and for some of them we identified negative demand shock. Hence this would imply the existence of idiosyncratic demand shocks within the EU.

Price responses to supply shocks are across the EU-15 more correlated than price responses to demand shocks. Price reactions to both supply and demand shocks are different for the analysed countries. We can say that price reactions of some countries are asymmetric with others. Countries affected by the same (positive) supply shock demonstrate different price adjustment dynamics and hence we see asymmetric price responses.

Concerning the speed of adjustment to shocks (we focused on supply shocks), within the whole group of analysed countries exist just few differences in the speed of adjustment of output to supply shocks.

\section{Reference}

BABETSKI, J., BOONE, I., MAUREL, L. (2003): Exchange Rate Regimes and Supply Shocks Asymmetry: the Case of the Accession Countries. Charles University, CERGE-EI: Working Paper Series, No. 206.

BAYOUMI, T., EICHENGREEN, B. (1992): Shocking Aspects of European Monetary Unification. Cambridge: National Burea of Economic Research Working Paper, No. 3949.

BLANCHARD, O.J., QUAH, D. (1989): The Dynamics Effects of Agreggate Demand and Supply disturbances. American Economic Review 79: 655-673.
CIPRA, T. (2008): Finanční ekonometrie. Praha: Ekopress. 1. vydání.

FIDRMUC, J., KORHONEN, I. (2003): Similarity of Supply and Demand Shocks Between the Euro Area and the CEEC's. Bank of Finland: BOFIT Discussions Paper, No. 14/2003.

FRENKEL, M., NICKEL, CH. (2002): How Symmetric Are the Shocks and the Shock Adjustment Dynamics Between the Euro Area and Central and Eastern European Countries? IMF: International Monetary Fund Working Paper, No. 02/222.

MUNDELL, R. (1961): A Theory of Optimum Currency Areas. American Economic Review 51(4): 657665. Available at: <http://www.tfasinternational.org/ ai-

pes/academics/vesetheconomics/econ2006folder/econr eadingday7no2.pdf $>$.

LÜTKEPOHL, H., KRÄTZIG, M. (2007): Applied Time Series Econometrics. Cambridge: Cambridge University Press.

\section{Additional sources}

LÜTKEPOHL, H., KRÄTZIG, M., BOREIKO, D. (2006): VAR Analysis in JMulTi. Available at: http://www.jmulti.de/.

OECD. Stat Extracts. Quarterly National Accounts. Gross Domestic Product (Deflator). Data extracted on 26.11.2009.

OECD. Stat Extracts. Quarterly National Accounts. Gross Domestic Product - Expenditure Approach (Millions of US dolars). Data extracted on 18. 06. 2009. 
DSpace VSB-TUO http://hdl.handle.net/10084/90123 